\title{
The role of GAP-analysis in reducing the uncertainty of online marketing results for SBEs
}

\author{
Artoym Kovalenko ${ }^{1, *}$, Irina Okolnishnikova ${ }^{2}$, and Yulia Kuzmenko ${ }^{1}$ \\ ${ }^{1}$ South Ural State University (National Research University), 76, Lenin Avenue, 454080, \\ Chelyabinsk, Russia \\ ${ }^{2}$ The State University of Management, 99, Ryazansky Prospect, 109542 Moscow, Russia
}

\begin{abstract}
Modern online marketing consists of a variety of interacting methods and tools. The consumer exists in the flows of marketing information. The consumer's value acquisition process is not linear. Financial constraints at the marketing budget level for small business enterprises require reducing the uncertainty of results from the applied online marketing methods. In this paper, we look into the properties of gap analysis to study the discrepancies between the current and planned results of online marketing activities of small business enterprises. The research methodology is based on the gap analysis method, which is complemented by the methods of content analysis, cvp analysis, graphical methods, and special methods of online marketing. The study examines the properties of gaps in the transformation of online marketing informational flows. A mathematical description and graphic interpretation of the gap in the transformation of the informational flow of online marketing is proposed. The results of the study show that the use of gap analysis methods makes it possible to detail the phenomenon of consumer proactivity, reduce the uncertainty from the use of online marketing methods and improve the quality of marketing information about the consumer for small business enterprises.
\end{abstract}

\section{Introduction}

Online marketing provides wide opportunities for small business enterprises to interact with target audiences. The peculiarities of the small business enterprises' activities are characterized by limitations that affect the effectiveness of online marketing methods and tools application. Key constraints such as marketing budget and variety of communication channels make it difficult to measure marketing performance and create control problems. On the one hand, online marketing is the basis of the marketing activities of enterprises and organizations [1]. On the other hand, small business enterprises do not have the competence to conduct online marketing activities [2].

The specificity of control problems leads to the attraction of marketing expert subjects, the development of outsourcing, and marketing consulting [3]. In particular, the activities of SEO, SMM, PPC - specialists who perform certain online marketing functions - are widely

\footnotetext{
* Corresponding author: insmarkets@gmail.com
} 
represented. But, online marketing methods are characterized by being multichannel [4]. The effectiveness of using one method of online marketing jeopardizes the success of a small business in the market. This results in poor quality consumer information and poses problems of uncertainty in the outcomes of online marketing for small business enterprises.

According to the authors of this work, the solution to the problem of reducing the uncertainty of the results of online marketing activities is to study the interaction of marketing expert systems and small business enterprises. The main feature of this interaction is the gaps between the actual and planned characteristics of online marketing activities of small business enterprises.

Thus, the study aimed to determine the role of GAP analysis in reducing the uncertainty of the results of online marketing activities of small business enterprises.

Research objectives:

1) determining the specifics of the GAP analysis in the study of online marketing activities of small business enterprises;

2) identifying indicators for the study of online marketing activities of small business enterprises using the methods of GAP analysis;

3) forming a graphical interpretation of the impact on gaps in online marketing activities of small business enterprises.

In the first section of the work, we consider the features of consumer movement in marketing communication channels. We argue the validity of using the GAP analysis method in assessing the effectiveness of online marketing activities from the standpoint of the quality of marketing information. The second section identifies methods for investigating gaps in online marketing for small business enterprises. In the third section, we describe the features of GAP analysis in reducing the uncertainty of online marketing results for small business enterprises.

\section{GAP analysis in the transformation of marketing informational flows}

In the era of digital communications diversity, approaches to the study of consumer movement in marketing informational flows are highly relevant.

Marketing is viewed from the perspective of informational flows that describe the consumer in the process of making a decision that is valuable for the enterprise $[5,6]$. The concepts of permissive [7] and inbound marketing [8] define the consumer as a source of marketing informational flow. This judgment is contrasted with traditional marketing, where the main source of informational flow in the enterprise.

The term "getting proactive" [9] arises, which describes the sequences of interactions leading the consumer to purchase. Linear ways of moving the consumer to the enterprise in the process of acquiring value are becoming a thing of the past. The transformation of the classic "sales funnel" takes place $[10,11]$. The change in the stages of movement towards value is not reduced to a linear model, in contrast to classical concepts [12]. Consumers return to separate stages, go through them again, stop at separate stages for an indefinite period.

Following a link in a contextual advertising network, searching for an enterprise in a social network, subscribing to a newsletter, making a call, call back, etc. are described in the indicators for assessing the effectiveness of online marketing [13]. There are many points of contact with the company, but not all of them lead to the target action - a purchase. Edelman \& Singer [9] argue that it is necessary to optimize the individual customer experience at specific points of contact with the enterprise.

According to the authors of this work, the approaches discussed above are more relevant for medium and large businesses. Small business enterprises are characterized by a lack of financial resources for detailed consumer research. Management decisions are made in 
conditions of poor-quality consumer information and the results of online marketing activities are uncertain. For this reason, additional optimization of the interaction chain is required. Identifying interactions that not only generate positive customer experiences but the economic impact for the small business in the short term as well.

Thus, the study [3] reasonably points to the limited competence of small business enterprises in marketing. Small business owners and key representatives do not have marketing education but do possess market knowledge. The level of managerial competencies and the knowledge gap [14] limits development opportunities but allows a small business to operate in the chosen market. The concept of inbound marketing [8] focuses on the development of individual points of interaction between the enterprise and the consumer. Guerrilla marketing approaches [15] take a close look at the targeting tools that identify profitable customer segments for an enterprise.

In these works, the authors considered the problem of optimizing interaction with the consumer from different points of view. Namely - the definition of marketing impact characteristics, which is more likely to lead to the target action - a purchase.

It is necessary to pay attention to the stages that affect the cost of interaction with the consumer when developing the features of online marketing for small business enterprises. In economic science, the stages of interaction are considered from the standpoint of GAP analysis.

The marketing implications of the gap were considered in the work on the quality of customer service [16]. In this paper, the authors have identified five distinct types of gaps. In relation to our research, the Marketing Information Gap is of the greatest interest. Marketing Information Gap refers to the gap between consumer expectations and the expectations of business representatives.

When interpreting the features of GAP in the field of online marketing, it is worth noting that the gap between expectations is an important factor in assessing the chain of interactions. The reason a consumer does not advance further in the marketing informational flow depends on many factors. According to the authors of this paper, the information that underlies the interaction of consumer and business expectations is a key factor in the marketing gap. In the case of online marketing, consumer information interacts with business information.

The problem of determining the gaps between the points of contact that the consumer passes through is the measurement process. In online marketing, the consumer is considered in the unity of indicators of the communicative, conversion, and economic effect. Therefore, it becomes a problem to determine the fact of the gap in the indicators of assessing the effectiveness of online marketing.

Determining the fact of the formation of a gap in marketing informational flows must be considered from the standpoint of transforming marketing processes. What happens when the consumer becomes more valuable to the business in an economic sense? The work in the field of studying conversion argues that the consumer is approaching the point of influence on the cash flow of the enterprise. In a practical sense, the consumer who leaves the request expresses the intention to receive a commercial offer from the enterprise. The consumer becomes involved in the activities of the enterprise and goes through the conversion processes.

Thus, in [17], the conversion is considered as a set of tools for identifying consumers with behavioral characteristics that are valuable for the enterprise. Conversion rates reflect the level of adaptation of the points of presence of an enterprise on the Internet [18]. Pages with a high conversion rate are more likely to convert a potential consumer into a buyer and loyal customer of the business. Conversion combines the processes of attracting and retaining a consumer [19] and is a factor that compresses the marketing-advertising hierarchy [20]. It allows influencing the units of the target audience that form marketing informational flows. 
According to the authors of this article, the conversion should be considered as an indicator that describes the movement of the online marketing informational flow. Conversion characterizes the specific form of the gap. It is a separate type of online marketing process. It allows forming dependencies between indicators of communicative, conversion, and economic effect, which determine the chains of interaction.

The problem with online marketing for small business enterprises is the inability to use complex and expensive web analytics systems. But there is a need to study the factors that reduce the economic impact of online marketing activities. According to the authors of this work, gap analysis can act as a toolkit for highlighting the stage at which the transformation of the informational flow of online marketing is not cost-effective.

Thus, as proactive and non-linear consumer pathways develop, exploring the gaps can be an important element in improving the quality of marketing information and reducing the uncertainty of online marketing activities for small business enterprises.

\section{Methods}

The methods of this work are based on the gap analysis method, which allows comparing the current and future indicators of online marketing activities of small business enterprises. The method is complemented by content analysis of the properties of gaps in the online marketing activities of small business enterprises.

The CVP analysis method is used to interpret the gaps that describe the online marketing activities of small business enterprises in terms of assessing the economic impact. This method is used to determine the links between the indicators for various types of effects from online marketing activities evaluation. This paper examines the communication, conversion, and economic impact of online marketing activities of small business enterprises.

The boundaries of the online marketing environment for small business enterprises explored in this paper are defined using specific online marketing techniques. In particular, conversion research methods are used in online marketing. A graphical method of interpreting the data obtained is used to illustrate the research results.

\section{Results}

According to the authors of this paper, the study of gaps in the online marketing informational flow transformation is based on the study of consumer characteristics that have economic value for a small business. This allows the classic online advertising pricing models to be combined into a ratio to measure the value of online marketing informational flow sites (MIT).

$$
M I T=\frac{C_{\mathrm{MIT}}}{I M F_{\mathrm{MIT}}(C R)},
$$

Where:

$\mathrm{C}_{\text {MIT }}$ is the cost of obtaining the informational flow of online marketing;

$\mathrm{IMF}_{\mathrm{MIT}}$ is the online marketing informational flow, consisting of behavioral characteristics of target audience units;

$\mathrm{CR}$ is the transformation (conversion) of the informational flow, which determines the percentage of transitions between the stages of online marketing processes.

The expanded view of the coefficient allows showing the interaction of classic models for evaluating online advertising: 


$$
M I T=\frac{C_{\mathrm{MIT}}}{I M F_{\mathrm{MIT}} \times C R_{1} \times C R_{2} \times C R_{3} \times \ldots \times C R_{\mathrm{n}}},
$$

where $\mathrm{MF}_{\mathrm{MIT}} \times \mathrm{CR}_{1} \times \mathrm{CR}_{2} \times \mathrm{CR}_{3} \times \ldots \times \mathrm{CR}_{\mathrm{n}}$ - the product of the informational flow of online marketing and conversion rates, which characterizes the change in the number of units of the target audience at a certain stage of the online marketing informational flow transformation.

The economic impact is important for online marketing in small business enterprises. Taking into account these factors it allows moving on to assessing online marketing informational flows from the perspective of GAP analysis of gaps between the conversion process stages. This assessment is implemented by comparing the converted informational flow at each $\left(I M F_{M I T} \times \ldots \times C R_{n}\right)$ stage and the $\left(\mathrm{C}_{\mathrm{MIT}}\right)$ cost of receiving it. The costs of obtaining an online marketing information stream are relatively constant over the selected time frame, while conversion rates change. This allows setting consumers of a small business with the most targeted behavioral characteristics apart.

The gap in the transformation of the informational flow of online marketing is the mismatch between the actual $\left(M I T_{\mathrm{f}}\right)$ and planned $\left(\mathrm{MIT}_{\mathrm{p}}\right)$ behavioral characteristics of consumers. Clarifying the properties of the gap in the transformation of the informational flow of online marketing allows:

1) describing the differences between the behavioral characteristics of consumers;

2) detailing the marketing processes that form the state of consumer proactivity in the activities of small business enterprises.

A formula $\left(\mathrm{GAP}_{\mathrm{MIT}}\right)$ is proposed to identify the gap in the online marketing informational flow transformation.

$$
G A P_{\mathrm{MIT}}=\frac{M I T_{\mathrm{f}}-M I T_{\mathrm{p}}}{M I T_{\mathrm{f}}} \times 100 \% .
$$

where: $\mathrm{MIT}_{\mathrm{f}}$ is the actual value of the coefficient; $\mathrm{MIT}_{\mathrm{p}}$ is the planned value of the coefficient.

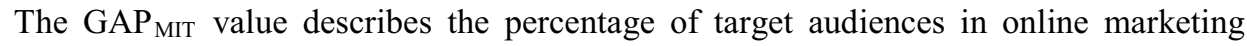
content conversion sites that reduce the impact of online marketing activities for small business enterprises. The calculated value is the cost of the number of target audience units that exceed the limits of the small business for the cost of online marketing activities.

Separate values of the MIT coefficient:

$$
\left(\frac{C_{\mathrm{MIT}}}{I M F_{\mathrm{MIT}}} \times C R_{1}\right) \text { and }\left(\frac{C_{\mathrm{MIT}}}{I M F_{\mathrm{MIT}}} \times C R_{1} \times C R_{2} \times \ldots \times C R_{\mathrm{n}}\right)
$$

form the pricing models of online marketing from CPC (cost of user's transition) to CPS (cost of the sale made by the user). So, the ratio of the costs of generating user transitions to pages and actual user transitions to a page $\left(\frac{C_{\mathrm{MIT}_{\mathrm{CL}}}}{I M F_{\mathrm{MIT}_{\mathrm{CL}}}}\right)$ is the cost of a certain number of user transitions - CPC (Cost per Click). This approach details the idea of consumer movement in marketing flows. The stages of the informational flow with the lowest conversion rates and/or the highest cost are gaps. These gaps form the points of application of efforts by the marketing expert and representatives of a small business enterprise.

The informational flow of online marketing is determined in the interaction of indicators of the communicative, conversion, and economic effect. Conversion processes detail the transformation of a communicative effect into an economic effect. Thus, the gap in the 
transformation of marketing informational flows can be determined in the system of inequalities (4).

$$
\left\{\begin{array} { l } 
{ \frac { C _ { \mathrm { MIT } _ { \mathrm { f } } } } { I M F _ { \mathrm { MIT } _ { \mathrm { f } } } C R _ { \mathrm { f } } } \leq \frac { C _ { \mathrm { MIT } _ { \mathrm { p } } } } { I M F _ { \mathrm { MIT } _ { \mathrm { p } } } C R _ { \mathrm { p } } } } \\
{ I M F _ { \mathrm { MIT } _ { \mathrm { f } } } C R _ { \mathrm { f } } \geq I M F _ { \mathrm { MIT } _ { \mathrm { p } } } C R _ { \mathrm { p } } }
\end{array} \Rightarrow \left\{\begin{array}{l}
M I T_{\mathrm{f}} \leq M I T_{\mathrm{p}} \\
I M \mathrm{~F}_{\mathrm{MIT}_{\mathrm{f}}} C R_{\mathrm{f}} \geq I M F_{\mathrm{MIT}_{\mathrm{p}}} C R_{\mathrm{p}}
\end{array}\right.\right.
$$

where $I M F_{M I T_{\mathrm{f}}} C R_{\mathrm{f}}, I M F_{M I T_{\mathrm{p}}} C R_{\mathrm{p}}$ are the actual and minimum limiting quantitative characteristics of the informational flow of online marketing; $M I T_{\mathrm{f}}, M I T_{\mathrm{p}}$ are actual and maximum marginal cost characteristics of online marketing informational flow.

Quantitative characteristics describe the type and number of stages that a consumer goes through in the informational flow of online marketing. Cost characteristics are represented by the correlation of quantitative characteristics with the online marketing activities costs. Thus, the fulfillment of the inequality system shows the absence of gaps in the online marketing flow for the small business enterprise.

Let us consider a graphical illustration of identifying and bridging gaps in the transformation of online marketing informational flow based on Table 1. Suppose that the following values are relevant for a small business enterprise:

1) the maximum limit of cost characteristics (CPL) at the target query level is 700 roubles;

2) the minimum limit of quantitative characteristics in the form of the number of targeted queries (LD) is 5 units.

A graphic illustration of identifying and closing gaps in the informational flow of online marketing (IFOM) is presented in Figures 1 and 2.

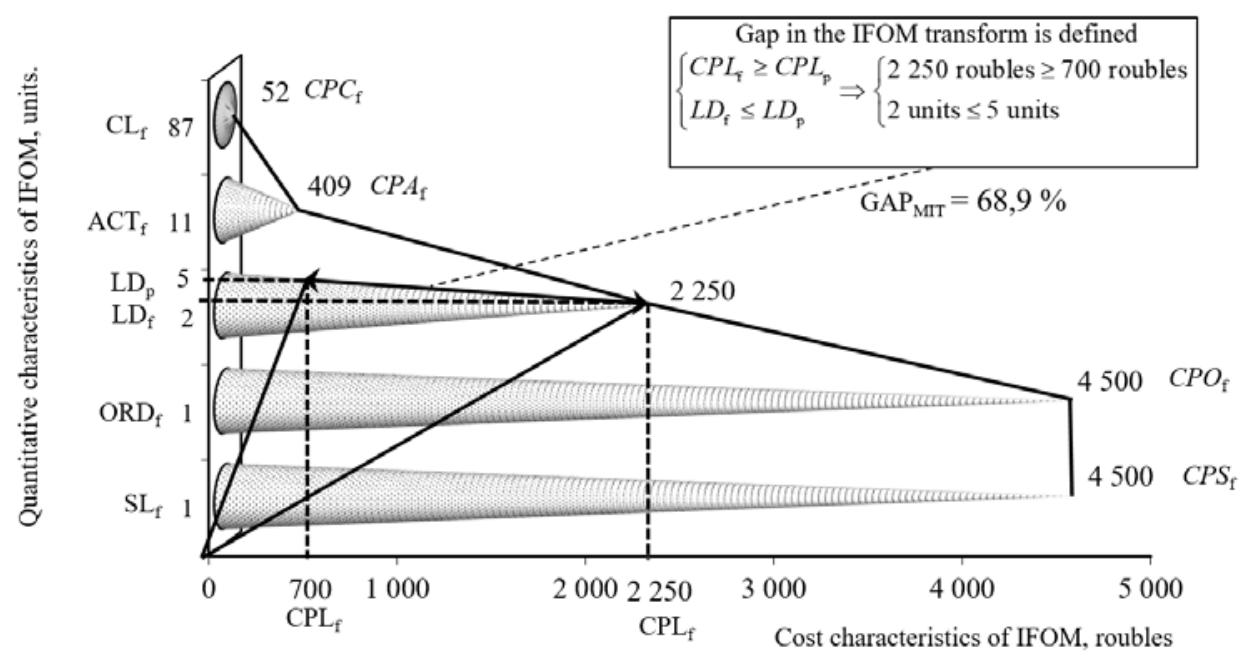

Fig. 1. Identifying the informational flow of online marketing (IFOM) transformation gap.

Notes: Subscript $\mathrm{f}$ - the actual value of the indicator; subscript $\mathrm{p}$ - the planned value of the indicator. Cost characteristics of IFOM are represented by the types of consumer behavioral characteristics: transitions to Internet sites (CL), actions (ACT), target queries (LD), orders (ORD), sales (SL). Quantitative characteristics of IFOM are represented by the cost of consumer behavioral characteristics: cost per click (CPC), action (CPA), target query (CPL), order (CPO), sale (CPS). _ - Informational Flow of Online Marketing (IFOM).

The graphic interpretation in Figure 1 reflects the process of forming a unit of the target audience - a consumer with behavioral characteristics that are valuable for a small business 
enterprise (in terms of economic effect). The graph is directed from top to bottom, has a shift along the abscissa by the value equal to the cost of the achieved behavioral characteristics. The authors of this work use the concept of behavioral characteristics to reflect the interaction of indicators of the communicative, conversion, and economic effect, which describe the properties of the consumer in the online marketing activities of small business enterprises.

The graphic interpretation in Figure 1 is based on hierarchical models of marketing communications. But, the specifics of online marketing allow noting the dynamism and variability in the hierarchy of stages that the consumer goes through in the process of moving towards value. Consequently, the decomposition of the online marketing informational flow can consist of several iterations that are economically feasible to determine the cause of the gap.

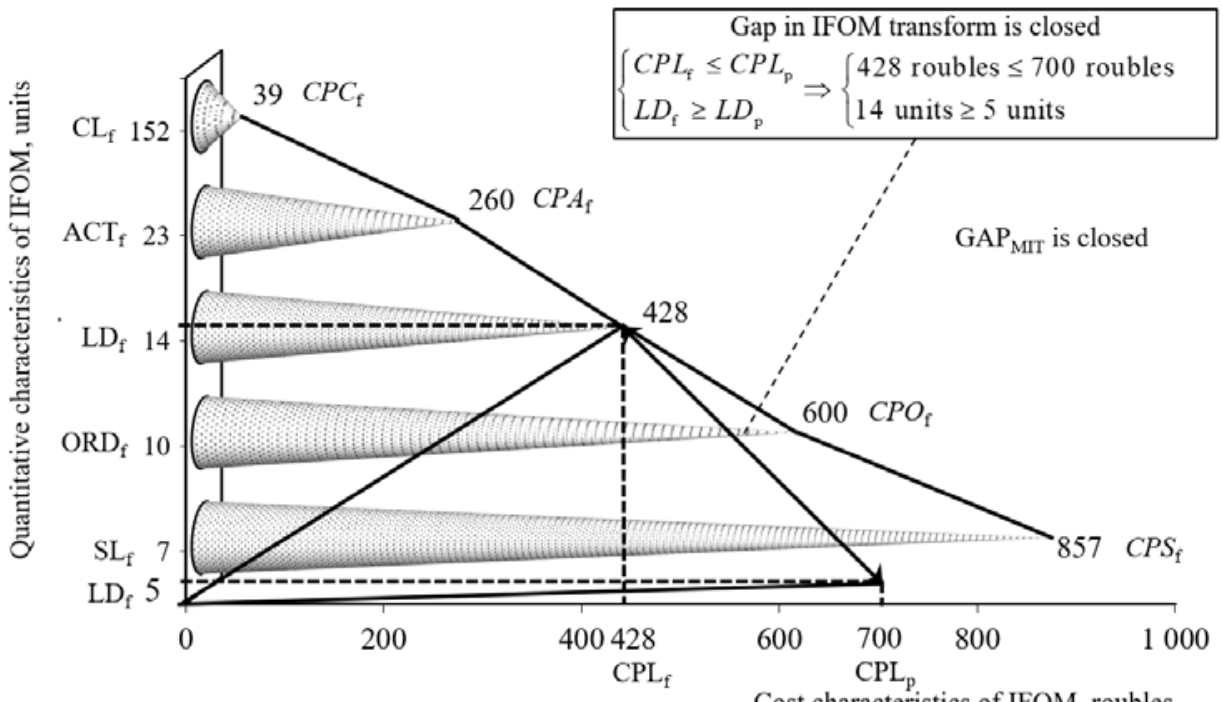

Fig. 2. Closing the gap in the informational flow of online marketing (IFOM).

The gap research approach simulates the economic impact of online marketing activities for small business enterprises (Table 1).

Table 1. Modeling the economic impact of online marketing activities for small business enterprises.

\begin{tabular}{|c|c|c|c|c|c|c|c|c|}
\hline \multirow[t]{2}{*}{ Indicator } & \multicolumn{2}{|c|}{$\begin{array}{c}\text { Communicative } \\
\text { effect, units }\end{array}$} & \multirow[t]{2}{*}{ Indicator } & \multicolumn{2}{|c|}{$\begin{array}{c}\text { Conversion effect, } \\
\%\end{array}$} & \multirow[t]{2}{*}{ Indicator } & \multicolumn{2}{|c|}{$\begin{array}{c}\text { Economic effect, } \\
\text { roubles }\end{array}$} \\
\hline & Before & After & & Before & After & & Before & After \\
\hline 1 & 2 & 3 & 4 & 5 & 6 & 7 & 8 & 9 \\
\hline$C L$ & 87 & 152 & - & - & - & $S R: \mathrm{CL}$ & 540.2 & $2,164.4$ \\
\hline$A C T$ & 11 & 23 & $\begin{array}{c}C R_{A C T-C L} \\
(A C T: C L \times 100)\end{array}$ & 12.6 & 15.1 & $S R:$ ACT & 4,272 & 14,304 \\
\hline$L D$ & 2 & 14 & $\begin{array}{c}C R_{L D-A C T} \\
(L D: A C T \times 100)\end{array}$ & 18.2 & 60.1 & $S R: \mathrm{LD}$ & 23,500 & 23,500 \\
\hline$O R D$ & 1 & 10 & $\begin{array}{c}C R O R D-L D \\
(O R D: L D \times 100)\end{array}$ & 50 & 71.4 & $S R:$ ORD & 47,000 & 32,900 \\
\hline$S L$ & 1 & 7 & $\begin{array}{c}C R_{S L-O R D} \\
(S L: O R D \times 100) \\
\end{array}$ & 100 & 70 & $S R: \mathrm{SL}$ & 47,000 & 47,000 \\
\hline \multicolumn{7}{|c|}{ Average Order Value (AOV) } & 47,000 & 47,000 \\
\hline \multicolumn{7}{|c|}{ Sales revenue (SR) $\backslash$ Sales (SL) * Average Order Value (AOV) } & 47,000 & 329,000 \\
\hline
\end{tabular}

Notes: communicative effect indicators: $\mathrm{CL}$ - transitions of users on the website; ACT actions of users on the website; LD - target queries of users on the website; ORD - the 
number of orders made by users on the website; $\mathrm{SL}$ - the number of purchases that users have made on the website. Conversion effect indicators describe the interaction of communication effect indicators. Economic impact indicators describe the cost of communicative impact indicators.

According to the authors of this work, the features of modeling the economic effect in Table 1 are:

1) Achieving a balance between the communicative, conversion, and economic effect assessment indicators. The example from Table 1 shows the dependence of the revenue of a small business enterprise on the achieved behavioral characteristics of the consumer. This example is based on considering the properties of CVP analysis to study online marketing activities. The cost of a consumer with given behavioral characteristics depends on the optimal interaction of indicators of the communicative, conversion, and economic effect.

2) The dynamics and variability in the hierarchy of stages that the consumer goes through are taken into account. Special attention to the impact on the company's revenue is paid by the authors of this article in their approach which is relevant for the small business sphere.

3) The main restrictions in the marketing activities of small business enterprises are considered. Gap research can be applied in the absence of complex and expensive analytical systems that are not available to small business enterprises. The data from a simple analytical system (Google.Analytics, Yandex.Metrika) and data on customer purchases that each small business uses is enough to apply the method.

Thus, GAP analysis allows considering online marketing activities as the interaction of communicative, conversion, and economic effects generated by various methods of online marketing.

\section{Conclusion}

In the course of the study, the authors examined the features of modern online marketing from the standpoint of transforming marketing informational flows. The problems of proactivity and nonlinearity of consumer paths in the marketing activities of small business enterprises phenomenon are detailed. The adaptation of the GAP analysis method to the study of online marketing is proposed. The results of the study allowed the authors to draw the following conclusions:

1) GAP analysis allows assessing the interaction of indicators of the communicative, conversion, and economic effect. This makes it possible to compare points of contact with the consumer based on the economic benefit to the small business.

2) GAP analysis allows identifying the boundaries of the studied consumer path based on online marketing pricing models. This makes it possible to consider the nonlinearity of the consumer path and highlight key points of contact between the enterprise and the consumer.

3) GAP analysis is applicable in the absence of complex and expensive analytical systems that are not available to small business enterprises. This type of analysis in online marketing makes it possible to identify the consumer segments that have economic value for the enterprise with high accuracy. This helps to reduce the level of uncertainty in online marketing activities' results for small business enterprises.

A possible limitation of this study is the consideration of online marketing conversion processes disregarding probabilistic specifics. GAP analysis consistently eliminates factors that contribute to the level of uncertainty in online marketing activities for small business enterprises. But, in our opinion, a quantitative assessment of probability will allow describing the properties of GAP analysis for online marketing activities of small business enterprises in a more detailed form. Consequently, the problems of predicting conversion rates, which form a gap in the informational flow of online marketing are areas for further research. 


\section{Acknowledgements}

The reported study was funded by RFBR, project number 19-310-90021.

\section{References}

1. R. Sidorchuk, Marketing Management of Business Activity of Small Businesses (theoretical and methodological aspect) (Plekhanov Russian University of Economics, Moscow, 2013)

2. Visual Capitalist. Visualizing the Evolution of Global Advertising Spend (1980-2020) https://www.visualcapitalist.com/evolution-global-advertising-spend-1980-2020/

3. P. Alford, S. J. Page, SIJ 35, 665-669 (2015) doi: 10.1080/02642069.2015.1062884

4. L. Kakalejčík, J. Bucko, P.A.A. Resende, M. Ferencova, JAMI 7(1), 49-60 (2018)

5. T. Novak, D. Hoffman, Y. Yung, MKSC 13(1), 22-42 (2000)

6. P. De Cleen, Flow marketing: Content, Conversatie, Conversie: Go with the flow (Lannoo Campus, Amsterdam, 2018)

7. S. Godin, D. Peppers, Permission Marketing: Turning Strangers into Friends and Friends into Customers (Simon \& Schuster, New-York, 1999)

8. B. Halligan, D. Shah, Inbound Marketing: Attract, Engage, and Delight Customers Online (John Wiley \& Sons, Upper Saddle River, 2014)

9. Harvard Business Review. Competing on Customer Journeys (2015) https://hbr.org/2015/11/competing-on-customer-journeys

10. M. Pietrzykowski, Fostering Entrepreneurial and Sales Competencies in Higher Education (Bogucki Wyd, Poznań, 2019) doi: 10.12657/9788379862801-5

11. A. Venermo, J. Rantala, T. Holopainen, Proceedings of International Conference on Applied Human Factors and Ergonomics, AHFE (San-Diego, CA, USA, 2017) doi: 10.1007/978-3-030-50791-6_25

12. P. Kotler, K.L. Keller, Marketing Management (Pearson Education Limited, Harlow, 2016)

13. J.R. Saura, P. Palos-Sanchez, L.M. Cerda-Suarez, FI 9(76), 1-13 (2017) doi: 10.3390/fi9040076

14. J. Levinson, Guerilla Marketing: Easy and Inexpensive Strategies for Making Big Profits from Your Small Business (Houghton Mifflin Harcourt, New-York, 2007)

15. A. Parasuraman, L.L. Berry, V.A. Zeithaml, HRM 30(3), 335-364 (1991) doi: 10.1002/hrm.3930300304

16. M.I. Ukolov, Organization of an advertising campaign for large online retailers (Moscow, MESI, 2007)

17. D. Herhausen, D. Miocevic, R. Morgan, M.H.P. Kleijnen, IMM 90, 276-290 (2020) doi: 10.1016/j.indmarman.2020.07.022

18. Y. Durmaz, I.H. Efendioglu, GJMBR 16(2), 34-40 (2016)

19. J.L. Garcia, D. Lizcano, C.M.Q. Ramos, N. Matos, FI 11(6), 130 (2019) doi: 10.3390/fi11060130

20. E.V. Saprykina, Marketing imperatives for the development of online advertising in the modern communication space (DGAU, Rostov-on-Don, 2012) 